\title{
Analysis of Mathematic Reasoning Ability and Self-Confidence Students Using Models PBL Reviewed from Intelligence Intrapersonal in SMP N 5 Youth Vocationality
}

\author{
Sujoko Waluyo, Dian Armanto, Abil Mansyur \\ Medan State University Postgraduate
}

\begin{abstract}
The instruments used are reasoning ability tests, self-confidence questionnaires, intrapersonal intelligence questionnaires and interview guidelines. Data analysis used the Mile and Huberman model. Subjects in this study involved students of SMP N 5 Vocational Youth who were given problem-based learning treatment with a total of 30 people. Intrapersonal intelligence of students with problem-based learning models, high-ability students as many as 8 students or $(26.67 \%)$, students with moderate abilities as many as 18 students or $(60 \%)$ and students with low ability as many as 4 people or (13.34\%). The conclusion of mathematical reasoning ability using problem-based learning model, high-ability students as many as 7 students or (23.33), moderately capable students as many as 13 students or (43.33\%) and low-ability students as many as 10 students or (33.33\%) ).
\end{abstract}

Keywords:Mathematical reasoning ability, Self-Confidence, PBL Model

DOI: $10.7176 / \mathrm{JEP} / 12-16-08$

Publication date: June $30^{\text {th }} 2021$

\section{PRELIMINARY}

According to the Law of the Republic of Indonesia No. 20 of 2003 concerning the National Education System Chapter I Article 1 that "Education is a conscious and planned effort to create a learning atmosphere and learning process so that students actively develop their potential, society, nation and state". (Shah, 2014). In the implementation of educationteacher is a salIt is a profession that demands professionalism in its work, especially in teaching. Teacher professionalism is the key to the smoothness and success of the learning process in schools. Teachers are said to be professional if they have high work skills and sincerity to teach as well as possible and are able to make students think, behave and act creatively.Zahroh, 2015).

Learning can run effectively if the teacher can condition all the components of learning properly and appropriately, but teachers are also required to have creativity to improve the quality of learning such as mathematics teachers must have interesting learning strategies so that students are interested in learning mathematics. Thank youand Fathani, 2008). Mathematics is one of the subjects studied by students starting from elementary school (SD) to university. This happens because mathematics is an important learning and has many benefits as stated by Fiad, Suharto and Kurniati (2017) "Mathematics is a basic science that plays an important role in the development of science and technology, because mathematics is a means of thinking to develop reasoning power. , logical, systematic and critical way of thinking".

While Siagian (2016) stated that "Mathematics is one of the branches of science that has an important role in the development of science and technology, both as a tool in the application of other fields of science and in the development of mathematics itself." Furthermore, Sundayana (2016) said that "mathematics is one of the components of a series of subjects that have an important role in education". Based on the two opinions above, it is concluded that the purpose of learning mathematics is to understand mathematical concepts, be able to solve problems, communicate ideas with symbols, tables, graphs, diagrams in explaining the state of things and develop respect for each other and shape the character of children.

National Council of Teachers of Mathematics (2000) set five basic mathematical abilities that must be mastered by students in learning mathematics, namely "(1) learning to communicate (mathematical communication), (2) learning to reason (mathematical reasoning), (3) learning to solve problems (mathematical problem solving), (4) to link ideas (mathematical connection) and (5) the formation of a positive attitude towards mathematics (positive attituded toward mathematics)".

One of the abilities that students need to have is the ability to reason as a standard that must be developed. Mathematics learning in schools must be able to prepare students to have mathematical reasoning abilities as a provision to face the challenges of development and change. According to Ruseffendi (2006) that "mathematics is formed as a result of human thinking related to ideas, processes and reasoning".

Mikrayanti (2016) states that "Mathematics is knowledge of logical reasoning and knowledge of logical structures". Based on this definition, developing mathematics requires logical, objective, systematic and creative thinking as well as high and structured reasoning. Therefore, the Ministry of National Education (Shadiq, 2008) states that "mathematical material and mathematical reasoning are two things that are closely related and cannot be separated because mathematical material is understood through reasoning and trained through learning 
mathematics".

Furthermore, Ball, Lewis and Thamel (Riyanto and Siroj, 2011) say "mathematical reasoning is the foundation for the construction of mathematical knowledge", meaning that mathematical reasoning is the foundation for obtaining or constructing mathematical knowledge. Based on the opinion above, it is concluded that reasoning is an activity, a process, an activity that connects new knowledge with existing knowledge to draw conclusions or make a new statement that is true.

In addition to mathematical reasoning ability, one of the affective abilities that affect students' success in solving math problems is self-confidence. According to Lestari and Yudhanegara (2015) self-confidence is an attitude of being confident in one's own abilities and seeing oneself as a complete person. Meanwhile, Ismawati (Amalia, 2015) defines self-confidence as a person's belief in being able to behave as expected and desired and a person's belief that he or she can master a situation and produce something positive.

Self-confidenceNurkholifa, Toheri and \& Winarso (2018) say that self-confidence has an important function to actualize the potential possessed by students and with self-confidence, students will be more motivated and prefer to learn mathematics. Zamnah and Ruswana (2018) say that self-confidence is an important element in achieving success.

According to Fitriani (2016) if someone has high self-confidence, then he will always try to develop everything that becomes his potential. Based on research conducted by Markku, Hanna and Pehkonen (2004) shows that learning mathematics is influenced by one's belief in mathematics, especially self-confidence. Selfconfidence in the aspect of learning mathematics is a student's belief about self-competence in mathematics. According to Wolfson (2015), self-confident people have many ambitious goals and will persist in difficult problems, which will always take advantage of opportunities.

Students who have high self-confidence will tend to be active in learning and trigger positive interactions between students and teachers as well as between students and students. The need for self-confidence that students have in learning mathematics is not accompanied by the facts, there are still many students who do not have self-confidence, this can be seen in some student behavior in learning where students do not dare to ask questions when having difficulties, do not dare to express opinions in front of them. class, as well as in discussions and less active role in learning, students tend to be passive in learning.

\section{THEORETICAL FRAMEWORK}

\section{Reasoning Ability}

Sumartini (2015) Reasoning is "an activity or thought process to draw conclusions or make new statements based on previous statements and the truth has been proven". Meanwhile, according to Keraf (Shadiq, 2004) that "reasoning is an activity, a process or a thinking activity to draw conclusions or make a new statement that is true based on several statements whose truth has been proven or assumed previously". The ability to find a pattern or nature of all mathematics to make generalizations is the ability of students to find patterns or methods from an existing statement so that it can be developed into mathematical sentences.

If a thought process has a basis of truth, then the thinking process is a process of drawing conclusions that is carried out in a certain way and requires rules to obtain the truth. In mathematics, the process of drawing conclusions to obtain the truth can be done by inductive and deductive reasoning.

\section{Mathematical Reasoning Ability}

Basically, the application of reasoning has been used by students during the mathematics learning process in class. This can be seen from the statement from the Ministry of National Education (in Shadiq, 2004) that "mathematical material and mathematical reasoning are two things that cannot be separated, namely mathematical material is understood through reasoning and reasoning is understood and trained through learning mathematics". Thus, every mathematical problem solving requires reasoning abilities and training students' reasoning skills can be done through the provision of specially designed questions, so that students are accustomed to solving problems by developing their thinking and reasoning processes.

"Mathematical reasoning is the foundation for obtaining or constructing mathematical knowledge by using reasoning on patterns and properties, performing mathematical manipulations and making generalizations, compiling proofs or explaining mathematical ideas and statements (Bani, 2011)". With the ability to reason mathematically, solving mathematical problems can be done by thinking logically and giving reasons for a solution. Therefore, mathematical reasoning is needed to determine whether an argument or mathematical statement is true or false, so that students feel confident that mathematics can be understood, thought out, proven and can be evaluated.

Based on the description above, it can be concluded that mathematical reasoning is the ability to carry out procedural solutions to mathematical problems and provide reasons for solving problems.

\section{Self-Confidence}

Self-confidenceor self-confidence is the extent to which there is confidence in the assessment of the ability to succeed. Bandura (Nurqolbiah, 2016) self-confidence is confidence in one's ability to touch and harden the 
motivation and resources needed and bring them into action in accordance with what must be completed, or in accordance with the demands of the task.

McElmeel (Martyanti, 2016) revealed that confidence is a faith or belief in oneself and one's own abilities to succeed. It is the belief that one will act in a right, proper, or effective manner. That is, self-confidence is a belief in oneself and one's own ability to achieve success. Self-confidence is also a belief that a person will act correctly, and according to an effective way.

McElmeel (Maryanti, 2016) revealed that related to mathematics, self-confidence is a belief about one's competence in mathematics and one's ability in mathematics which is the result of the process of learning and practicing math problems. The ability of students to work on the mathematical problems they face helps students have confidence in their abilities.

Fricha (Haeruman, Rahayu and Ambarwati, 2017) self-confidence is self-confidence in the abilities and strengths of students so that they are able to solve a given problem in a good and effective way according to the observed aspects. Lestari and Yudhanegara (2015) say self-confidence is an attitude of being confident in one's own abilities and seeing oneself as a complete person with reference to self-concept.

\section{RESEARCH METHODS}

The subjects in this study were class VIII students of SMPN 5 Vocational Youth for the 2020/2021 Academic Year.The objects in this research are mathematical reasoning ability and students' confidence in solving mathematical problems through a problem-based learning model at SMP N 5 Vocational Muda. The object of this research can be seen from the results of students' mathematical reasoning ability tests through student answer sheets, reasoning questionnaires and interviews in the form of transcripts of voice or video recordings obtained by researchers from the interview process, either interviews with students or interviews with teachers during the study.

\section{RESEARCH RESULT}

The main purpose of this study is to analyze mathematical reasoning abilities and self-confidence by using a problem-based learning model in terms of students' intrapersonal intelligence and to analyze reasoning difficulties experienced by students in solving problems of mathematical reasoning abilities using problem-based learning models in terms of intrapersonal intelligence kecerdasan. This study obtained a number of data which include: (1) the results of the mathematical reasoning ability test, (2) the results of a self-confidence questionnaire and (3)reasoning difficulties experienced by students in solving problems of mathematical reasoning abilities using problem-based learning models.

\section{Level of Mathematical Reasoning Ability}

The students' mathematical reasoning ability was obtained from the results of the mathematical reasoning ability test and interviews. All student answer sheets are collected to be checked and given an assessment (score). The assessment of students' answers refers to the guidelines for scoring mathematical reasoning abilities. After getting the total value of each student's answer, then categorized based on the level of mathematical reasoning ability. The level of mathematical reasoning ability can be seen in Table 1 below.

Table 1 Mathematical Reasoning Ability Level

\begin{tabular}{|c|c|c|c|}
\hline Value Interval (Percentage) & Total students & Student Percentage & Rating Category \\
\hline 70 & 7 people & $23.33 \%$ & High \\
\hline$>50-70$ & 13 people & $43.33 \%$ & Medium \\
\hline$\leq 50$ & 10 People & $33.33 \%$ & Low \\
\hline
\end{tabular}

Based on the table above, it can be seen that the level of students' mathematical reasoning abilities taught using a problem-based learning model obtained an interval of 70 in the high category as many as 7 people or $23.33 \%$. Then, the number of students who obtained value intervals $>51-71$ in the medium category were 13 people or $43.33 \%$. Furthermore, the number of students who obtained an interval of 50 in the low category was

10 people or $33.33 \% . \leq$

\section{2 level Self-Confidence}

Self-confidence students obtained from the results of self-confidence questionnaires and interviews. All student answer sheets are collected to be checked and given an assessment (score). The assessment of students' answers refers to the students' self-confidence scoring guidelines. After getting the total score from each student's answer, then they are categorized based on the level of self-confidence. The level of self-confidence ability can be seen in Table 2 below. 
Table 2 Ability Level Student Self-Confidence

\begin{tabular}{|c|c|c|c|}
\hline Value Interval (Percentage) & Total students & Student Percentage & Rating Category \\
\hline 70 & 9 people & $30.00 \%$ & High \\
\hline$>50-70$ & 18 People & $60.00 \%$ & Medium \\
\hline 550 & 3 people & $10.00 \%$ & Low \\
\hline
\end{tabular}

Based on the table above, it can be seen that the level of self-confidence of students taught using a problembased learning model obtained an interval of 70 in the high category as many as 9 people or $30.00 \%$. Then, the number of students who obtained value intervals $>50-59$ in the medium category were 18 people or $60 \%$. Furthermore, the number of students who obtained an interval of 50 in the low category was 3 people or $10.00 \%$. $\leq$

\section{Level of Intrapersonal Intelligence}

The ability of students' intrapersonal intelligence was obtained from the results of intrapersonal intelligence questionnaires and interviews. All student answer sheets are collected to be checked and given an assessment (score). The assessment of students' answers refers to the guidelines for scoring students' intrapersonal intelligence. After getting a total score from each student's answer, then categorized based on the level of intrapersonal intelligence. The level of intrapersonal intelligence can be seen in Table 3 below.

Table 3 Intrapersonal Intelligence Level

\begin{tabular}{|c|c|c|c|}
\hline Value Interval (Percentage) & Total students & Student Percentage & Rating Category \\
\hline 70 & 8 people & $26.67 \%$ & High \\
\hline$>50-70$ & 18 People & $60 \%$ & Medium \\
\hline$\leq 50$ & 4 people & $13.34 \%$ & Low \\
\hline
\end{tabular}

Based on the table above, it can be seen that the level of intrapersonal intelligence of students taught using a problem-based learning model obtained an interval of nilai 70 in the high category of 8 people or $26.67 \%$. Then, the number of students who obtained value intervals $>50-69$ in the medium category were 18 people or $60 \%$. Furthermore, the number of students who obtained an interval of 50 in the low category was 4 people or $13.34 \% . \leq$

\section{Subject Picking}

Criteria for taking subjects who are subject to interviews using criteria that are based on indicators of student abilities. The research subjects adjusted to the indicators of students' abilities were grouped into three categories, namely (1) high, (2) medium and (3) low; The three categories become a reference to see students' reasoning abilities and self-confidence.

Based on the results of the intrapersonal intelligence questionnaire that has been examined and measured by scoring guidelines, the subjects are selected to be interviewed according to their level of intrapersonal intelligence ability. The selected ability categories interviewed are shown in Table 4.4 as follows:

Table 4 Selected Categories for the Mathematical Reasoning Ability Interview andSelf-Confidence

\begin{tabular}{|c|c|c|c|c|}
\hline \multirow{2}{*}{$\begin{array}{c}\text { Intrapersonal } \\
\text { Intelligence }\end{array}$} & $\begin{array}{c}\text { Mathematical } \\
\text { Reasoning } \\
\text { Ability }\end{array}$ & \multicolumn{3}{|c|}{ Self-Confidence } \\
\cline { 3 - 5 } & High & TKI.TKPM.TSC & TKI.TKPM.SSC & TKI.TKPM.RSC \\
\hline \multirow{4}{*}{ High } & Medium & TKI.SKPM.TSC & TKI.SKPM.SSC & TKI.SKPM.RSC \\
\cline { 2 - 5 } & Low & TKI.RKPM.TSC & TKI.RKPM.SSC & TKI.RKPM.RSC \\
\hline \multirow{4}{*}{ Medium } & High & SKI.TKPM.TSC & SKI.TKPM.SSC & SKI.TKPM.RSC \\
\cline { 2 - 5 } & Medium & SKI.SKPM.TSC & SKI.SKPM.SSC & SKI.SKPM.RSC \\
\cline { 2 - 5 } & Low & SKI.RKPM.TSC & SKI.RKPM.SSC & SKI.RKPM.RSC \\
\hline \multirow{4}{*}{ Low } & High & RKI.TKPM.TSC & RKI.TKPM.SSC & RKI.TKPM.RSC \\
\cline { 2 - 5 } & Medium & RKI.SKPM.TSC & RKI.SKPM.SSC & RKI.SKPM.RSC \\
\cline { 2 - 5 } & Low & RKI.RKPM.TSC & RKI.RKPM.SSC & RKI.RKPM.RSC \\
\hline
\end{tabular}

Information:

TKI = High Intrapersonal Intelligence

skiing = Moderate Intrapersonal Intelligence

RKI = Low Intrapersonal Intelligence

TKPM = High Reasoning Ability

SKPM = Moderate Reasoning Ability 


\section{RKPM = Low Reasoning Ability \\ TSC $\quad=$ High Self-Confidence \\ SSC $\quad=$ Medium Self-Confidence \\ RSC $\quad=$ Low Self-Confidence}

Based on the table above, the subject was obtained to be subjected to an interview in accordance with his mathematical reasoning ability. The selected subjects who were interviewed are shown in the following table.

Table 4 Sample of Selected Students For Mathematical Reasoning Ability Interview and Self-Confidence

\begin{tabular}{|c|c|c|c|c|}
\hline Intrapersonal & $\begin{array}{c}\text { Mathematical } \\
\text { Reasoning } \\
\text { Ability }\end{array}$ & High & Medium & Low \\
\cline { 3 - 6 } & High & $\begin{array}{c}\text { S-2, S-6, and S- } \\
21\end{array}$ & - & - \\
\hline \multirow{4}{*}{ High } & Medium & S-8 & S-44 & - \\
\cline { 2 - 5 } & Low & S-19 and S-20 & S-22 and S-26) & - \\
\hline \multirow{4}{*}{ Medium } & High & - & S-27 and S-29 & - \\
\cline { 2 - 5 } & Medium & S-18 & $\begin{array}{c}\text { S-1, S-3, S-5, S-7, S-9, S- } \\
10, \text { S-12 and S-23 }\end{array}$ & $\begin{array}{c}\text { S-17 and S- } \\
24\end{array}$ \\
\cline { 2 - 5 } & Low & S-11 and S-14 & S-13, S-15 and S-16) & - \\
\hline \multirow{4}{*}{ Low } & High & - & S-25 and S-3 & - \\
\cline { 2 - 5 } & Medium & - & - & - \\
\cline { 2 - 5 } & Low & - & - & S-28 \\
\hline
\end{tabular}

Based on the table above, it can be seen that the group of reasoning ability and self-confidence in terms of intrapersonal intelligence based on high, medium, and low can be grouped as follows.

a. Students who have high intrapersonal intelligence, high reasoning ability and high self-confidence (3 students out of 30 students or $10,00 \%$ ).

b. Students who have high intrapersonal intelligence, moderate reasoning ability and high self-confidence (1 student out of 30 students or $3.34 \%$ ).

c. Students who have high intrapersonal intelligence, moderate reasoning ability and moderate selfconfidence (1 student out of 30 students or $3.34 \%$ ).

d. Students who have high intrapersonal intelligence, low reasoning ability and high self-confidence (2 students out of 30 students or $6.67 \%$ ).

e. Students who have high intrapersonal intelligence, reasoning ability low and moderate self-confidence (2 students out of 30 students or $6.67 \%$ ).

f. Students who have moderate intrapersonal intelligence, high reasoning ability and moderate selfconfidence ( 2 students out of 30 students or $6.67 \%$ ).

g. Students who have moderate intrapersonal intelligence, moderate reasoning ability and high selfconfidence (1 student out of 30 students or 3.34\%).

h. Students who have moderate intrapersonal intelligence, moderate reasoning ability and moderate selfconfidence ( 8 students out of 30 students or $26.67 \%$ ).

i. Students who have moderate intrapersonal intelligence, moderate reasoning ability and low selfconfidence (2 students out of 30 students or $6.67 \%$ ).

j. Students who have moderate intrapersonal intelligence, low reasoning ability and high self-confidence (2 students out of 30 students or $6.67 \%$ ).

k. Students who have moderate intrapersonal intelligence, low reasoning ability and moderate selfconfidence ( 3 students out of 30 students or $10.00 \%$ ).

1. Students who have low intrapersonal intelligence, high reasoning ability and moderate self-confidence ( 2 students out of 30 students or $6.67 \%$ ).

m. Students who have low intrapersonal intelligence, low reasoning ability and low self-confidence ( 1 student out of 30 students or $3.34 \%$ ).

\section{BIBLIOGRAPHY}

Amalia, Y., Duskri, M. Ahmad, A. (2015). Application of Eliciting Activities Model to Improve Mathematical Creative Thinking Ability and Self-Confidence of High School Students. Journal of Didactic Mathematics. 2(2), 38-48.

Bani, A. 2011. Improving Mathematical Comprehension and Reasoning Ability of Junior High School Students Through Guided Discovery Learning. Unpublished Thesis. Bandung: SPs UPI Bandung. 
Ministry of National Education. 2003. National Education System Law. Jakarta: Ministry of National Education.

Ministry of National Education. 2006. Permendiknas No. 22 of 2006 concerning Content Standards. Jakarta: Ministry of National Education.

Fiad, U., Suharto. \& Kurniati, D. 2017.Identification of Mathematical Literacy Ability of SMP Negeri 12 Jember Students in Solving PISA Questions on Space And Shape Content. Kadikma, 8(1): 72-78.

Fitriani, N. 2016. The Relationship between Mathematical Problem Solving Ability and Self-Confidence of Junior High School Students using Realistic Mathematics Education Approach. Euclid's Journal, 2(2): 251365.

Haeruman., Rahayu. \& Ambarwati. 2017.The Effect of the Discovery Learning Method on the Improvement of Mathematical Critical Thinking Ability and Self-Confidence in terms of the Early Mathematical Ability of High School Students in East Bogor. Journal of Mathematics Research and Learning. Vol. 10, No.2

Lestari, KE \& Yudhanegara, MR (2015). Mathematics Education Research. Bandung: PT Refika Aditama

Maryanti, A. 2016.The Effectiveness of Problem Solving Approach With Stad and Tai Settings Judging from Presentation and Self-Confidence. Journal of Mathematics Education Research. Vol. 3, No.1

Masykur \& Fathani, AB 2008. Mathematical Intelligence. Yogyakarta: Ar-ruz Media Group.

Mikrayanti. 2016. Improving Mathematical Reasoning Ability Through Problem-Based Learning. Suska Journal Of Mathematical Education, 2(2): 97-102. p-ISSN: 2477-4758.

National Council of Teachers of Mathematics (NCTM). 2000. Principles and Standards for School Mathematics. Reston: VA.

Nur, SK, Winarso, W. \& Toheri. 2018.The Relationship between Self-Confidence with Students' Critical Thinking Ability in Mathematics Learning. Edumatica, 8(1): 58-66.

Riyanto, B. \& Siroj, R. 2011. Improving Reasoning Ability and Mathematics Achievement with Constructivism Approach in High School Students. Journal of Mathematics Education, 5(2): 111-127.

Ruseffendi. 2006. Introduction to Helping Teachers Develop Competencies in Teaching Mathematics. Bandung: Tarsito.

Shadiq, F. 2008. Middle School Mathematics Learning Models. Jakarta: Nurul Hidayah.

Sadiq. 2004. Problem Solving, Reasoning and Communication. Yogyakarta: PPPG Teacher Upgrading Paper.

Siagian, MD 2016. Mathematical Connection Ability in Mathematics Learning. Journal of Mathematics Education and Science, 1(2): 58-67. ISSN: 2528-4363.

Soedjadi. 2009. Contextual Problems as Joint Stones in School Mathematics. Surabaya: Central

Sundayana, R. 2016. Media and Teaching Aids in Mathematics Learning. Bandung: Alphabeta.

Shah, M. 2014. Educational Psychology. Bandung: PT Pemuda Rosdakarya.

Tan, Chin Pei \& Molen, Ht \& Schmidt, HG. (2016). To What Extent Does Problem-Based Learning Contribute To Students' Professional Identity Development?. Teaching and Teacher Education. 54. 54-64. 10.1016/j.tate.2015.11.009.

Wolfson, N. (2015). Behavioral EQ Explorations. TRACOM Group.

Zamnah, LN \& Ruswana, AM 2018.The Relationship Between Student Self-Confidence and Mathematical Understanding Ability in the Capita Selekta Mathematics IV Lecture. JTAM, 2(1):57-61.

Zahroh, A. 2015. Building the Quality of Learning through the Dimensions of Teacher Professionalism. Bandung: CV Yrama Widya. 